\title{
Müllerian duct anomalies-limb anomalies syndrome
}

INSERM

\section{Source}

INSERM. (1999). Orphanet: an online rare disease and orphan drug data base. Müllerian duct anomalies-limb anomalies syndrome. ORPHA:2491

Mullerian duct anomalies-limb anomalies syndrome is characterised by the association of mullerian duct and distal limb anomalies. It has been described in five individuals from one family. Females presented with anomalies ranging from a vaginal septum to complete duplication of uterus and vagina, and males presented with micropenis. The limb anomalies varied from postaxial polydactyly to severe upper limb hypoplasia with split hand. The mode of transmission is autosomal dominant. 